\title{
Metal Nanoparticles Embedded Electrode Materials for Chemical and Biosensor Applications
}

\author{
Osamu Niwa ${ }^{1}$, Shota Takahashi ${ }^{1}$, Tatsuya Machida ${ }^{1}$, Tomoyuki Kamata ${ }^{2}$, Shunsuke Shiba ${ }^{1,2}$, Dai Kato $^{2}$ \\ ${ }^{1}$ Saitama Institute of Technology, 1690, Fusaiji, Fukaya, Saitama, 369-0293 Japan, \\ ${ }^{2}$ National Institute of Advanced Industrial Science and Technology (AIST), Central 6, 1-1-1 Higashi, \\ Tsukuba, 305-8566 Japan \\ niwa@sit.ac.jp
}

\begin{abstract}
Metal nanoparticles embedded in the carbon film electrodes were fabricated by co-sputtering of two metals and carbon and applied for detecting heavy metals such as selenium and arsenic, and also detecting sugar markers for the diagnosis of severe intestinal diseases. For improving the sensitivity for detecting heavy metal ions, the Au was plated on the surface of $\mathrm{Au}$ nanoparticles embedded electrodes and uniform nanoparticles with larger surface area can be fabricated and achieved to detect $\mathrm{As}^{3+}$ and $\mathrm{Se}^{4+}$ with low detection limit around $10 \mathrm{ppb}$. For detecting sugar markers, we fabricated $\mathrm{Ni}$ and $\mathrm{Cu}$ nanoalloy embedded in the carbon film and achieved the detection limits about 2 order of magnitude lower than that of commercially available gold electrode.
\end{abstract}

Key words: Nanocarbon, Electrode, Nanoparticles, Heavy metal, Sugar, Biomarker

\section{Introduction}

Metal nanoparticles (NPs) modified electrodes show very high electrocatalytic activity for not only hydrogen oxidation and oxygen reduction for fuel cells but also various analytically important molecules including gases, heavy metals and many biomolecules. However, conventional modification processes such as physical adsorption and electrochemical plating often caused aggregation or detachment of metal NPs due to poor adhesion between the electrode and NPs. In contrast, we have developed metal NPs embedded in the carbon film electrodes by using co-sputtering of carbon and metals and applied for detecting various molecules such as hydrogen peroxide, acethylcholine and sugars [1, 2]. Since most of each NP was tightly embedded in the stable carbon film, suppressing aggregation and/or detachment of each NP from the electrode surface. Here we report two kind of NPs embedded carbon film electrodes, one is $\mathrm{Au}$ NPs embedded carbon film electrodes for detecting heavy metal ions such as arsenic $\left(\mathrm{As}^{3+}\right)$ and selenium $\left(\mathrm{Se}^{4+}\right)$ ions, the other is $\mathrm{Ni}$ and $\mathrm{Cu}$ alloyed NPs (nanoalloy) embedded carbon films for detecting sugars with highly improved detection limit.

Au NPs embedded carbon film electrodes detecting $\mathrm{As}^{3+}$ and $\mathrm{Se}^{4+}$ ions
We used unbalanced magnetron (UBM) cosputtering equipment [2] with three target system for fabricating the electrodes. When detecting $\mathrm{As}^{3+}$ and $\mathrm{Se}^{4+}$ ions, Au NPs embedded carbon film electrode was used for anodic stripping voltammetry (ASV). In case of low surface area of NPs appeared on the electrode surface, we plated Au on the surface of $\mathrm{Au}$ NPs to increase the active surface area. The film surface is relatively flat before $\mathrm{Au}$ plating (Figure 1(a)), but NPs with a few to
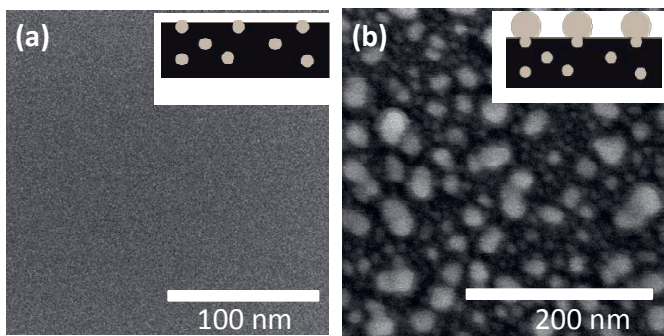

Figure 1 SEM image of (a) Au NPs embedded carbon film electrode and (b) Au plated Au NPs embedded carbon film electrode

several tens nanometers were observed at the surface (Figure 1(b)). The distribution of AuNPs is more uniform compared with the electrode $\mathrm{Au}$ plated on the pure carbon film because embedded AuNP works as core of Au growth. Figure 2 shows relationship between the results by ASV and ICP-MS for $\mathrm{As}^{3+}$ measurement with 


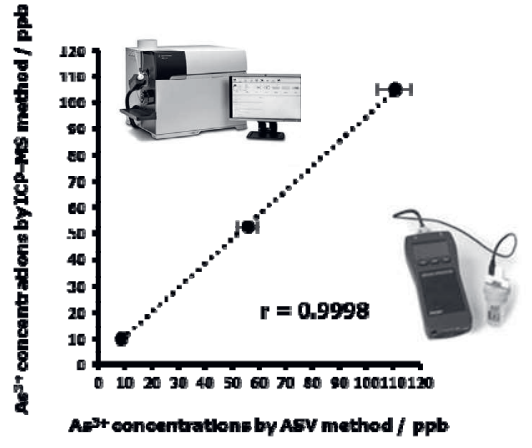

Figure 2 Correlation between the analytical results obtained by our ASV and ICP-MS method for tap water containing $\mathrm{As}^{3+}$ ions.

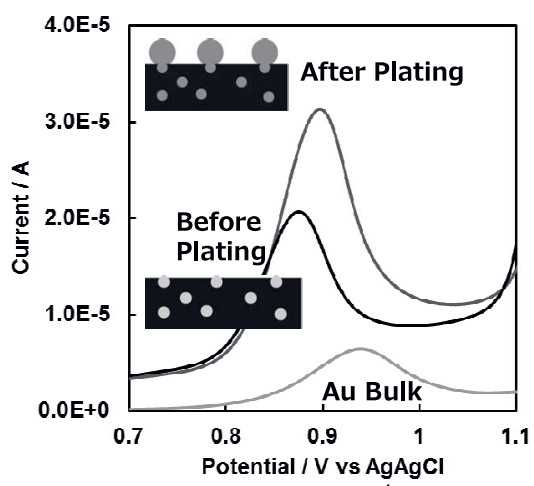

Figure $3 \mathrm{ASV}$ of $1 \mathrm{ppm} \mathrm{Se} \mathrm{S}^{4+}$ obtained by the $\mathrm{Au}$ NPs embedded carbon film before and after $\mathrm{Au}$ plating compared with that of Au bulk electrode.

the electrode shown in Figure 1 (a). The effect of interferences from $\mathrm{Cu}^{2+}$ was easily removed by adding EDTA [3]. A linear relationship with $\mathrm{R}^{2}$ of 0.993 was obtained with tap water samples. In contrast, the sensitivity of $\mathrm{Se}^{4+}$ was not sufficient. we compared the sensitivity and detection limits of both electrodes shown in Figure 1. The sensitivity and detection limit of plated electrode (b) was higher than the electrode (a) before plating due to increased NPs size as shown in Figure 3.

\section{Detection of clinical sugar markers}

We also fabricated Ni/Cu nanoalloy embedded carbon film electrodes for detecting clinical sugar markers. The $\mathrm{Ni} / \mathrm{Cu}$ ratio and concentration of nanoalloy could be widely controlled by changing each sputtering power [4]. The electrocatalytic activities of above electrodes were studied in the alkaline solution by measuring 5 clinical sugar markers including D-mannitol for the diagnosis of severe intestinal diseases. Figure 4 shows sensitivity of 5 sugar markers by changing Ni/Cu ratio. The electrode with $\mathrm{Ni} / \mathrm{Cu}=61 / 39$ shows highest sensitivity compared with other nanoalloy embedded electrodes and bulk electrode. The electrode is also very stable compared with $\mathrm{Ni} / \mathrm{Cu}$ alloy (without carbon film matrix) indicating of high

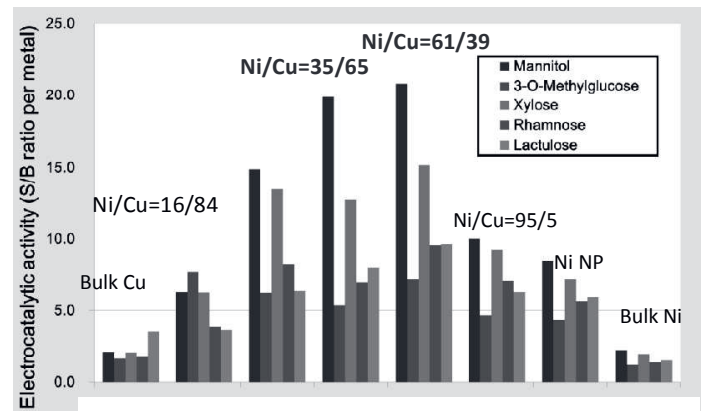

Figure 4 Variation of the sensitivity for 5 clinical sugar markers at $\mathrm{Ni} / \mathrm{Cu}$ nanoalloy embedded carbon film electrodes by changing $\mathrm{Ni} / \mathrm{Cu}$ ratio

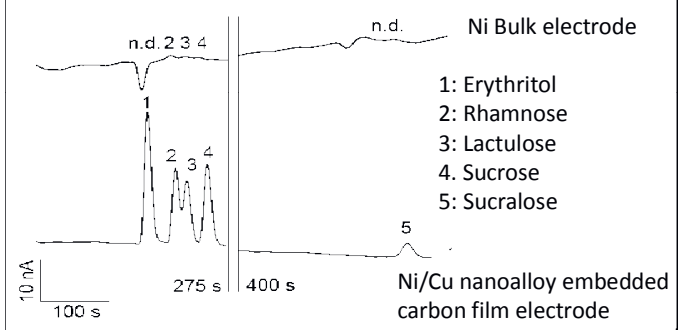

Figure 5 Chromatogram of 5 clinical sugar markers at the $\mathrm{Ni} / \mathrm{Cu}$ nanoalloy embeded carbon film electrode compared with that of Ni bulk electrode

electrocatalytic activity of $\mathrm{Ni} / \mathrm{Cu}$ nanoalloy. Figure 5 shows chromatograms for 5 sugars compared with that of $\mathrm{Ni}$ bulk electrode. The peak of each sugar is very clear at $\mathrm{Ni} / \mathrm{Cu}$ nanoalloy embedded carbon film electrode. In contrast, each peak is not clear at the Ni bulk electrode. Our electrode shows the detection limit of a few tens nanomolar/L, which is about 2 order of magnitude lower than those at $\mathrm{Ni}$ bulk electrode.

\section{References}

[1] T. You, O. Niwa, M. Tomita, S. Hirono, Characterization of platinum nanoparticleembedded carbon film electrode and its detection of hydrogen peroxide, Anal. Chem., 75, 20802085 (2003)

[2] T. Kamata, D. Kato, H. Ida, O. Niwa, Structure and electrochemical characterization of carbon films formed by unbalanced magnetron sputtering method, Diamond \& Related Materials, 49, 25-32 (2014)

[3] Daiki Kato, T. Kamata, D. Kato, H. Yanagisawa, O. Niwa, Au nanoparticle-embedded carbon films for electrochemical $\mathrm{As}^{3+}$ detection with high sensitivity and stability, Anal. Chem., 88, 29442951 (2016)

[4] S. Shiba, D. Kato, T. Kamata, O. Niwa, Cosputter deposited nickel-copper bimetallic nanoalloy embedded carbon films for electrocatalytic biomarker detection, Nanoscale, 8, 12887-12891 (2016). 